\section{Qualitative Inquiries into Social \\ Representations of Health}

UWE FLICK

Alice-Salomon University of Applied Sciences and Technical University, Berlin, Germany

UWE FLICK is Professor for Empirical Nursing Research at the Alice-Salomon University of Applied Sciences, Berlin, and Privatdozent in Psychology at the Technical University of Berlin, Germany. His main research interests are everyday knowledge, social representations, subjective theories, qualitative methodology, individual and public health and technological change in everyday life.

ACKNOWLEDGEMENTS. This article has benefited from a grant from the Deutsche Forschungsgemeinschaft (FL245/5-1).

COMPETING INTERESTS: None declared.

ADDRESS. Correspondence should be directed to:

DR UWE FLICK, Alice-Salomon-Fachhochschule, Alice-Salomon-

Platz 5, D-12627 Berlin, Germany.

[Tel. +49 30992454 11; Fax +49 30811218 7;

email: flic0730@mailszrz.zrz.tu-berlin.de]
Journal of Health Psychology

Copyright (c) 2000 SAGE Publications

London, Thousand Oaks and New Delhi, [1359-1053(200007)5:3]

Vol 5(3) 315-324; 013533

\section{Abstract}

Concepts of health and illness have been a major topic for social representations research. Whereas studies on cognitive representations of health and illness develop a general, decontextualized schema of illness, social representations research focuses on the diversity of lay concepts of health and illness and how health and illness are socially constructed in different contexts. Two qualitative studies about the social representations of health are presented. The episodic interview and theoretical coding were used to study health concepts of nurses and clerks in East and West Germany and among Portuguese and German women. Results in both studies show different forms of awareness of health as the core of the health concepts in the various groups. Social representations theory connects these differences back to the political and cultural backgrounds of the study participants.

\section{Keywords}

cultural differences, health concepts, qualitative methods, social representations 
LAY REPRESENTATIONS of health and illness have been a topic of investigation for cognitive psychologists for at least two decades. Leventhal, Meyer, and Nerenz (1980) inaugurated a series of studies about cognitive representations of health and illness that have provided a general model. The illness schema model includes representations of concrete symptoms, a label to identify a health problem, causes, direct and long-term consequences of the problem, its temporal course, and the means of healing. These findings have been criticized for several reasons. The cognitive models ignore social differences in such representations. The studies do not link their findings to the social or cultural contexts to explain why people perceive health and illness the way they do and why they differ in their conceptions. Furthermore, most of these studies used abstract stimulus materials and student populations as informants. They have also ignored the social and cultural contexts of these cognitive representations (see Murray, 1990, for more details).

Social representations theory focuses on such contextual issues. The studies in this approach often use qualitative methods and use specific questions to obtain answers that are related to the concrete circumstances in which the informants live. They also link the findings to the social and cultural contexts of the people they study.

\section{Social representations and health}

The theory of social representations was introduced by Moscovici (1961/1976) for the purpose of studying the different representations of psychoanalysis in various social groups. Moscovici (1998, p. 243) has recently provided a definition of social representations. On the one hand he defined a social representation as being organized similarly to a theory, with a core statement, related propositions that are combined with examples, and a hierarchy of values and models of action. On the other hand he defined them as being more fluid than theories but rather a 'network of ideas, metaphors and images'. New processes and experiences and changes are anchored in social representations, which means that they are named and categorized in ways typical for social groups and objectified in metaphors and images. This theory has been used to study 'hot topics' (Moscovici, 1988) which are new or changing in a way that disturb or frighten people or a society and which lead to changes in a broader knowledge system (see Farr \& Moscovici 1984; Flick, 1998a, for overviews). For example, the appearance of AIDS has led to changes and a re-evaluation of knowledge about illness, sexuality, social groups (homosexuals, for example) and so on (see Campbell, 1998). These changes of knowledge have occurred differently in various social groups (see Flick, 1998c).

Health and illness have been central topics in the research on social representations. Herzlich (1969/1973) studied the social representations of health and illness in France. She found three types of health conceptions and three types of illness conceptions in her interviews. This project has stimulated much research about representations of health and illness and their social distribution in society (e.g. Pill \& Stott, 1982). Jodelet (1991) analysed the existing representations linked to mental illness and to the mentally ill in a village in France, where a large part of the population made their living by hosting ex-patients in their own families. To find out how these representations influenced daily life in this village, Jodelet used ethnographic methods and interviewed the families hosting the ex-patients. The study shows how a naive theory of mental illness is the core of the social representations of madness in this village. This theory was strongly influenced by the fear of contagion and of getting too close to the ex-patients. It could be used to explain a variety of practices in the villages that were in strong contrast to the 'official' aim of integrating the ex-patients. Jodelet illustrated the changing discourses of mental illness and related them to the changing practices with the patients in the village.

These two studies are the most prominent studies on the social representations of health and illness. There have been several others going in similar directions, but most of these more or less focus on the social representation of a specific illness-like madness in the case of Jodelet's research. Studies that focus explicitly on the social representation of health are still rare. 


\section{Qualitative methods in the study of social representations of health: examples}

Some findings of two of our own recent studies of social representations of health are detailed here. In both studies, the data were collected using the episodic interview (Flick, 1998b, 2000) as a specific method for studying everyday knowledge. This interview includes questions on subjective definitions of the topic under study, on relations among concepts used by the interviewees (Table 1 , question 1) and on more abstract or general relations (Table 1, question 2). The answers to this part of the interview revealed the interviewee's network of meanings related to a topic like health. The more central part of the interview asked for narratives of situations in which the topic became relevant in the interviewee's actual everyday life or had become relevant in his or her biography (Table 1, question 3). Also chains of situations could be mentioned (Table 1, question 4). Another aspect is changes the interviewee imagines, expects or is afraid of (Table 1, question 5).

The data were analysed by using the coding procedures suggested by Strauss (1987): open coding was applied to (the most relevant excerpts of) the interviews. For example, an East German male nurse gave the following definition of health:

Well I link personally to health the complete functionality of the human organism, all the biochemical processes of the organism, including all the circulations, but also the mental state of my person and of Man in general...

Open coding of this passage generated three codes referring to the following parts of the definition: 'complete functionality' was coded as functionality, normative claim; 'of the human organism' was coded as mechanistic image of Man; 'all the circulations' was coded as mechanistic-somatic idea of health.

Codes were then worked up by elaborating their underlying dimensions (axial coding). This was applied to the codes that were most instructive for the single interview and later for the social group of which the interviewee was part. Axial codes were, for example: responsibility, control, social milieu, subjective well-being, change, nutrition, relation body-psyche, norms, illness, health activities.

The paradigm model of Strauss (1987) was applied to elaborate these codes further. In the end, a core category was developed-first for every interview, then for every group of interviewees and finally for the whole set of interviews (selective coding). These core categories were then applied to the whole data set again in order to find out their explanatory power.

\section{Health concepts of East and West German clerks and nurses}

Our first study took Herzlich (1969/1973) as a starting point to collect health concepts from different social groups (Flick, 1998d). Two professional groups (nurses and clerks) from the former East and West German parts of Berlin between the ages of 30 and 50 years were interviewed. These groups were chosen for the following reasons. First, to compare health professionals with non-health professionals. In Germany, nurses and clerks have similar levels of education and income. We expected that comparing these two groups would show how their health concepts differed and how similar they were. We also wanted to find out how a professional link to health led to differences in dealing with health matters in everyday life

Table 1. Sample questions used in episodic interviews about health

1. What is 'health' for you? What is related to the word 'health' for you?

2. In your opinion, who should be responsible for your health? Who is able to take this responsibility?

3. When you look back and remember, when did you first think about health? Could you please tell me about that situation?

4. Please tell me how your day went yesterday and when the topic health played a role in it.

5. What developments do you expect in the area of health care in the near future? Please imagine and tell me a situation that could make this development clear for me. 
outside the professional sphere. Second, we included interviewees from East and West Berlin in order to find out how the differences in the health systems of the former German Democratic Republic and West Germany, as the biographical contexts of our interviewees, influenced expectations and evaluations with respect to health, health behaviour and health problems several years after the reunification of Germany. We found similarities across all groups. In many of our interviews, a much greater awareness of health-related topics became evident: topics like cycling instead of driving, fitness and healthy nutrition play a much bigger role than in Herzlich's study, so we added another type of health conception (health as lifestyle) to Herzlich's original typology of health and illness conceptions (1969/1973, p. 63 et seq.) (see Table 2):

Table 2. A typology of health and illness conceptions (modified after Herzlich, 1969/1973)

\begin{tabular}{ll}
\hline Health conceptions & Illness conceptions \\
\hline Health in a vacuum & Illness as destructive \\
Reserve of health & Illness as liberator \\
Health as lifestyle & Illness as occupation \\
Equilibrium & \\
\hline
\end{tabular}

Differences became clear in comparing all interviews and in comparing the interviews from the four groups systematically. The interpretation of the data led to core categories for the single interviewees (e.g. ascription of responsibility, internal need for control, living with illness, suppression, responsibility, control vs losing control) and to the following core categories for each group:

- Nurses from East Germany: need for control Here the dimensions are self- vs outside control (i.e. do I take responsibility for my health or is the state responsible?) and norms vs pleasure-oriented control (do I have to follow rules and norms or do I enjoy healthy living?)

- Clerks from East Germany: awareness of health

Dimensions are getting carried away without being unhealthy and health-oriented activities (e.g. to compensate stress).

- Clerks from West Germany: scepticism leads to alertness

Here the dimension is scepticism against orthodox medicine to alertness to alternative ways of preventing and treating illness.

- Nurses from West Germany: self-management of health and illness

Health and illness are seen more as the result of one's own activities than as the result of medical support.

These four groups were compared again and awareness of health as a central concept for organizing the field of health conceptions resulted from the interpretation of the interviews. This central concept is characterized by the dimension of reflexive dealing with health and suppression of the topic. Comparing the different groups showed differences in the way they dealt with the topic of health, so that the groups could be located at different points along this dimension (see Fig. 1).

The differences in these groups reflect different contextual conditions. The health system in West Germany was very differentiated with hospitals and doctors in private practice leaving a relatively big part to the individuals seeking help for a health problem or preventive care: They had to decide which institution to select and had to take care of their own health. The health system in the former GDR was centralized and took care of people's needs much more than our interviewees experienced in the new reunified Germany. In the former system, the policlinic

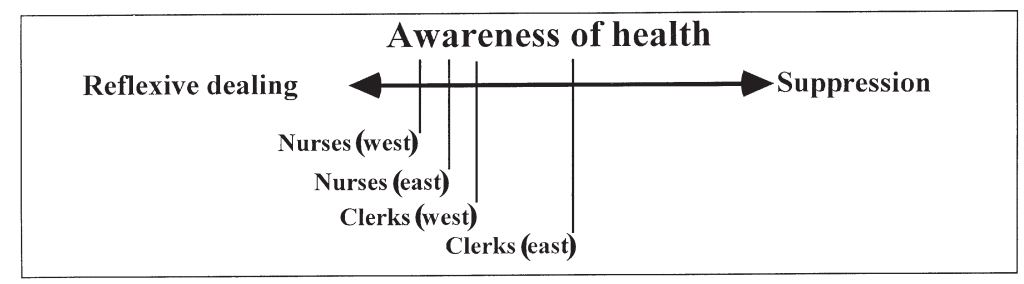

Figure 1. Differences in social groups' ways of dealing with health. 
was the institution to address. On the other hand, in the GDR, things like nutrition or pollution were rather neglected as factors influencing people's health. In the new system, much more awareness and self-responsibility are demanded in finding the right way of taking care for one's own health, with much more differentiated health services (see also NeumannOellerking \& Havel, 1999).

These changes were reflected in the core categories applying to our interviews with East Germans (need for control: nurses; awareness of health: clerks). This higher attention demanded by the West German system is also reflected in the core categories in West German interviews (scepticism leads to alertness: clerks; selfmanagement of health and illness: nurses). The professional focus on health led to a higher sensibility or awareness among the nurses compared to the clerks. Thus there is a double impact on the representations of health in the four social groups resulting from the differences in the health systems experienced in the biographies and from the professional proximity to or distance from the topic of health.

In this study, social representations of health were analysed against the background of two cultures. These cultures are characterized by common language and history in a longer perspective, but with very different value systems, health and political systems and ways of living for about 40 years during the existence of two German states. At the time when the interviews were done (1994), these two cultures were about to become integrated again.

\section{Health concepts of German and Portuguese women}

The second study ${ }^{1}$ focused on concepts of health of women in Portugal and Germany; more precisely in the capitals of the two countries: Lisbon and Berlin. Both cities are of about the same size. Portugal and Germany were chosen for this study as they are both part of the European Community, but at different ends of the scale: Germany is highly industrialized with a high gross national product (GNP) and a highly developed health system; Portugal is much less industrialized, has a much lower GNP and the health system was built up much more recently (after the end of the dictatorship in the 1970s).
Different from the former study, here the two cultures are characterized by different languages and historical backgrounds. Our interest in comparing Portugal and Germany resulted from these differences as both countries face an upcoming integration in the European Community which will lead to an integration in more and more fields in the long run. One of these fields will be the health system. We started by comparing Portugal and Germany for pragmatic reasons and hoped to be able to continue this comparison with other European countries.

The sampling of our informants in each of the cities focused on women living in comparable circumstances. We included women aged between 28 and 36 years, with similar education levels and working for example as secretaries, clerks or physiotherapists; half of the individuals in the sample in each of the cities had up to two children, the rest had no children. Women were chosen as other studies (Faltermaier, 1994; Graham, 1985) showed that they tend to be the health experts in the family, giving advice and practical support to other family members.

\section{Background: differences in the health systems}

To have an idea of the backgrounds in which conceptions of health in both groups develop and operate we gathered together selected data about both countries and their health systems (see Table 3).

These data also made evident that Germany has a well-developed health system in which 66 per cent of the costs are paid by contributions to the obligatory social security insurance system, depending on personal income. About 90 per cent of the population are members of this system of health insurance. The health system in Portugal (sistema nacional de saúde) was established in 1979, five years after the dictatorship ended. It is paid for mainly by the state (63 per cent), with a personal contribution of 20 per cent from the people. It is supposed to give everybody equal access to health services. The health system includes hospitals and health centres. General practitioners in private practice are not part of the public health system. Beyond this public health system, there is a private health system accessed by 25 per cent of the people. They are insured by their employers and can use private practitioners and hospitals. These 
Table 3. Comparison of Portugal and Germany on the level of statistical data

\begin{tabular}{|c|c|c|}
\hline & Portugal (Lisbon) & Germany (Berlin) \\
\hline Population in millions (1993) & 9.362 & 80.974 \\
\hline Inhabitants of the capitals in millions (1993) & 3.304 & 3.4657 \\
\hline \multicolumn{3}{|l|}{ Relation of general practitioners to specialists } \\
\hline & $73 \% / 27 \%$ & $42 \% / 58 \%$ \\
\hline Number of general practitioners & 1276 & 6218 \\
\hline Inhabitants per doctor & 1605 & 550 \\
\hline Number of hospitals & 30 & 98 \\
\hline Number of hospital beds & 7951 & 36,783 \\
\hline Hospital beds per 1000 inhabitants & 3.88 & 10.6 \\
\hline \multicolumn{3}{|l|}{ Money spent by the state for health (1990) } \\
\hline in $\%$ of the Gross National Product & 4.05 & 8.07 \\
\hline \$ per person & 383 & 1511 \\
\hline
\end{tabular}

Sources: Senatsverwaltung für Gesundheit (1993), Statistisches Bundesamt (1994), Ministerio de Saúde (1995), World Health Organization (1995)

differences have led to a two-class health system in Portugal. Table 3 shows that the numbers of general practitioners in both cities are very different as well as the numbers of inhabitants per general practitioner. Another difference can be found in the relations of general practitioners to specialists in each case. These figures show that the health system is much more developed in Berlin than it is in Lisbon and the services that are available in both cities differ in quantity and specialization.

Questions in the interviews were formulated in German and Portuguese and focused on definitions of health, descriptions of healthy people, the importance of health, conditions of health, knowledge about health and health activities, definitions and causes of illness, coping with illness and experiences with the health system. Analysis of the data focused on the similarities and differences between German and Portuguese women. Again the interviews were analysed using the method of Strauss (1987). The coding procedures were applied in a way similar to that mentioned above. They are supposed to lead to one central phenomenon or core category for the whole field under study or in comparative studies to one central phenomenon for each group. Here we found such a phenomenon for each country.

\section{Health of Portuguese women: lack of awareness}

The central phenomenon that reappeared in the interviews with Portuguese women again and again was lack of awareness (falta de cuidado). This term is difficult to translate into other languages but means 'not to take care of oneself, not to be cautious for oneself'. It seems to be a general problem in Portugal, that people do not care for themselves, and this was named by different interviewees as the main source of illness: 'I think that awareness is missing in the lives of the people, not only in their eating but also that they do not regularly visit the doctor'. For the women whom we interviewed, Portuguese people 'simply let things run'. They know that there are things they should do for their health (eating, stress reduction, sport, prevention), but they see themselves as not having enough initiative. As one interviewee put it: 'In my head, everything is there. But doing-it could be today, it could be tomorrow. It is today tomorrow and I will never do it'. The women see this contradiction in their knowledge and practice, for example: 'I should take more care of my health. I worry, but I don't go to the doctor, I let myself go'. Our interviewees attribute this lack of awareness to themselves or to the people in Portugal in general. But they also mention many reasons for this lack of awareness resulting from the Portuguese health system. One interviewee 
says: 'Whoever depends on the public health system might die in the meantime'. Waiting two or three months for an appointment with the doctor, waiting years for operations and waiting five to six hours at the health centre despite a fixed appointment are seen as quite normal:

You go to the health centre and wait for ages. The doctor is supposed to come at eight, but appears at ten and has to consult ten or twenty persons. And you are there and if you are ill, you will become more ill. Why? Because you get upset for waiting such a long time.

According to this interviewee the state does not take responsibility for creating the conditions to guarantee Portuguese people's health due to the poor technical equipment in the hospitals, lack of doctors and limited environmental care: 'Health is a duty the State has to give to the people'. The state contributes to the phenomenon of lack of awareness, as it produces barriers to health care, does not give people enough information, and does not motivate people enough to care for their health.

A possible explanation for understanding this lack of awareness can be found in the history of Portugal. Fatalism and resignation to one's own fate can be seen as a result of the long suppression of the population in the history from monarchy to military dictatorship, in the fascist governments of Salazar and Caetano until finally in 1974 the 'revolution of the carnations' brought democracy. Long years of suppression, poverty and limited education for working class people were the conditions for many generations. These experiences made it difficult for many people to take up their own interests and to take care of their own health. This might give one explanation of the phenomenon of 'lack of awareness' beyond individual behaviour.

\section{Health for women in Germany: being forced to health}

In the German interviews, the central phenomenon was the feeling of being 'forced to health'. On the one hand, interviewees linked it to their feeling that they have to be healthy; on the other hand they saw ill people being made outsiders by society and the media rather than being integrated in society. As one interviewee put it:

... the citizen is made an outsider by the media and the press and so on, is really forced to be in good shape. And this whole idea of health-who does not correspond to it, is an outsider then, as you are not accepted in our society in this way. A healthy, active, sportive human being is desired and is well accepted in the society. And people with an illness, they are marginalized, like AIDS, which is just an example.

This demand of being healthy, beautiful and fit is described as stressful. Being forced to health was discussed by all the German women whom we interviewed in a critical way. They felt under pressure by these internalized duties:

Yes I think, this obligation to health is indoctrinated to us, because we receive it from the media, we receive it from our surroundings, one almost could see it as global, we are permanently confronted with it. Who is fat is not good; who is ill is not good; who does not function is not good, disturbs the society in the end. I think, the duty of a good citizen, that's what is trained to us and somehow becomes clear everywhere.

The interviewees repeatedly stressed the importance of sport and healthy eating for their health. The knowledge mediated to them has become anchored in their social representations. The women did not only link negative impressions to being forced to health, but also positive ones. The information offered by media and health insurances was evaluated positively. The women felt informed and had developed a critical awareness towards traditional medicine. Rules of when and how often certain forms of prevention should be used were experienced as a relief:

Prevention-I keep somehow to clear rules like cancer screening and every six months a dental check-up. I have a bad conscience, if I do not go there every six months. Somehow, I can nicely hang on the system, because prevention comes by law which means it is laid down. It's a bit strange, but in this respect, our health care is so good, I have to go there, I go there, I make it easier than if I set my own rules for prevention.

And, as another woman put it:

Somehow, there is a moral forefinger, you 
have to stay healthy and have your dentist's appointment noted in your record, and when you have been there the last five years regularly, you will get a filling for free.

Our German interviewees reported that they are given the impression that health can be obtained if individuals take their part and take care of their own health. In these interviews, it became clear that being forced to health is a very ambivalent topic. Media and the health system provide information about prevention and healthy behaviour. Thus, individuals are given the impression that it is their behaviour that is the reason for becoming ill (blaming the victim: see Crawford, 1977). But, information about the 'right' behaviour was partly contradictory and became difficult for lay people to comprehend. In this society, health seems to be feasible under the condition that individuals follow the experts' suggestions. The danger in taking this perspective is that the responsibilities and influences beyond the individual (environment, pollution, conditions of work, deficiencies in the health system) tend to be ignored. Health may become an obligation and is closely linked to fear of falling ill. This sense of obligation leads sometimes to a feeling of being overchallenged, which was an implicit topic in many interviews with the German women. Figure 2 summarizes the central phenomena that we found in each group and mentions the most important factors that the informants linked to them.

\section{Similarities and differences}

Similarities could be found in the way in which health was defined explicitly by the interviewees. In addition, risks for one's own health, the relevance of health, fears abut illness, and knowledge about health-promoting behaviours were mentioned in a similar way in both groups.

A major difference was that our German interviewees reported that information about health was often obtained from family members, whereas the Portuguese women tended to obtain their knowledge on their own, from books, journals, television and doctors. The German women received their knowledge from 'Family, childhood, what mother and grandmother said. ..', as one interviewee put it. This traditional role of women, to take care of the health of their family members, was also found in other studies in Germany (e.g. Faltermaier, 1994). Another difference was that the Portuguese women put more stress on the role of the psyche for one's health than the German women in our study did: 'Health means that a human being is healthy in all physical and
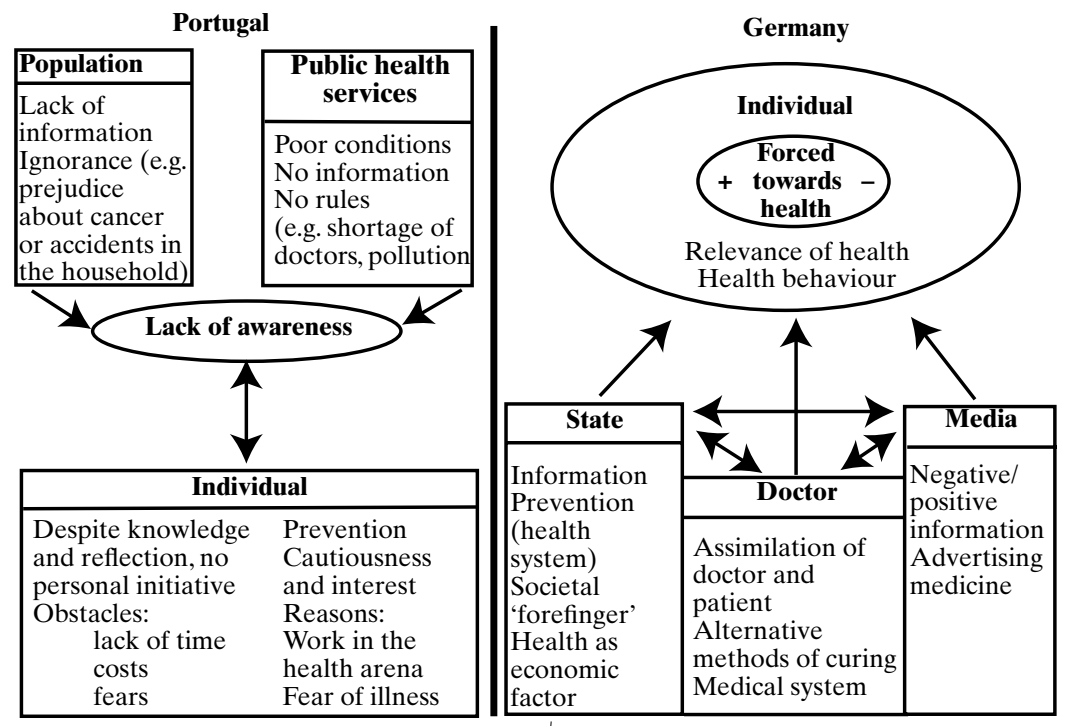

Figure 2. Central phenomena in health concepts of German and Portuguese women. 


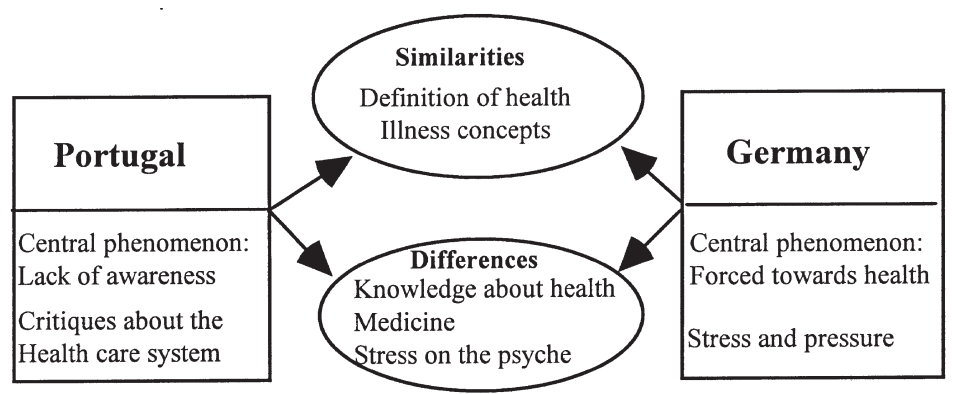

Figure 3. Similarities and differences in health concepts of Portuguese and German women.

psychological aspects'. German women mentioned this point in the interviews rather indirectly and talked more about physical complaints than about psychological aspects. The study showed shared aspects and differences summarized in Figure 3.

\section{Conclusions}

Both studies reported here do not claim for representiveness. They want to show how health conceptions are influenced by the concrete cultural, historical and social contexts in which they were made explicit. In the first case, the differences in the health conceptions responded to the different backgrounds in the health systems of the former East and West Germany and interviewees' experiences with these systems. Differences in the awareness of health can be explained with the changes after the reunification experienced by the interviewees from the former East Germany. There are better conditions (better nutrition, reduced pollution, more institutions) for maintaining one's health now but more decisions to be made by the individual (e.g. which institution to go to, which food to select, which means of transportation to use). Health awareness was different in both groups: Portuguese women felt a lack of awareness in their behaviour as well as in the way the state and the health system treated them with their health problems, whereas the German women saw themselves confronted with too much awareness of their health, experienced as being 'forced to health'. Social representations theory allows us to trace back such differences to social contexts and conditions. In both cases, more general experiences with the health systems and changes in it are anchored in the health conceptions and objectified in specific metaphors-of awareness and control. Health and illness in these examples-as in Herzlich's study (1969/1973) — became a 'mode of interpretation of society by the individual and [...] mode of relation of the individual to society' (p. 139). Such qualitative inquiries into social representations contextualize health and illness in concrete circumstances instead of decontextualizing them in abstract and general-cognitivemodels.

\section{Note}

1. The interviews were done by Petra Sitta and Beate Hoose.

\section{References}

Campbell, C. (1998). Representations of gender, respectability and commercial sex in the shadow of AIDS: A South African case study. Social Science Information, 37, 687-709.

Crawford, R. (1977). You are dangerous to your health: The ideology and politics of victim-blaming. International Journal of Health Services, 7, 663-680.

Faltermaier, T (1994). Gesundheitsbewusstsein. München: PVU.

Farr, R. M., \& Moscovici, S. (Eds.) (1984). Social representations. Cambridge: Cambridge University Press.

Flick, U. (Ed.) (1998a). Psychology of the social. Cambridge, Boston: Cambridge University Press.

Flick, U. (1998b). An introduction to qualitative research. London: Sage.

Flick, U. (Ed.) (1998c). Wann fühlen wir uns gesund? 
Subjektive Vorstellungen über Gesundheit und Krankheit [When do we feel healthy? Subjective representations of health and illness]. Weinheim und München: Juventa.

Flick, U. (1998d). Subjektive Vorstellungen von Gesundheit und Krankheit. Überblick und Einleitung. In U. Flick (Ed.) Wann fühlen wir uns gesund? Subjektive Vorstellungen über Gesundheit und Krankheit (pp. 7-30). Weinheim und München: Juventa.

Flick, U. (2000). Episodic interviewing. In M. Bauer \& G. Gaskell (Eds.), Qualitative researching with text, image and sound-a handbook (pp. 75-92). London: Sage.

Graham, H. (1985). Providers, negotiators, and mediators: Women as the hidden carers. In E. Lewin \& $\mathrm{V}$. Oleson (Eds.), Women, health, and healing (pp. 25-52). New York: Tavistock.

Herzlich, C. (1969/1973). Health and illness: A social psychological analysis. London: Academic Press.

Jodelet, D. (1991). Madness and social representations. Hemel Hempstead: Harvester Wheatsheaf.

Leventhal, H., Meyer, D., \& Nerenz, D. (1980). The commonsense representation of illness changes. In S. Rachman (Ed.) Contributions to medical psychology (Vol. 2). Oxford: Pergamon.

Ministerio de Saúde (1995). Elementos Estatisticos Saude/93. Lissabon: Departamento de Estudos e Planeamente da Saude.

Moscovici, S. (1961/1976). La psychanalyse, son image et son public. Paris: Presses Universitaires de France.
Moscovici, S. (1988). Notes towards a description of social representation. European Journal of Social Psychology, 18, 211-250.

Moscovici, S. (1998). The history and actuality of social representations. In U. Flick (Ed.), Psychology of the social (pp. 209-248). Cambridge, MA: Cambridge University Press.

Murray, M. (1990). Lay representations of illness. In P. Bennett, J. Weinman, \& P. Spurgeon (Eds.), Current development in health psychology (pp. 63-92). Chur: Harwood.

Neumann-Oellerking, D., \& Havel, M. (1999). Wandel in der hausärztlichen Versorgung im Freistaat Sachsen-eine Studie in der Landeshaupstadt Dresden. In DGfPH (Ed.), Public Health Forschung in Deutschland (pp. 87-93). Bern: Huber.

Pill, R., \& Stott, N. C. H. (1982). Concepts of illness causation and responsibility: Some preliminary data from a sample of working-class mothers. Social Science and Medicine, 16, 43-52.

Senatsverwaltung für Gesundheit. (1993). Jahresgesundheitsbericht 1993 für Berlin. Berlin.

Statistisches Bundesamt. (1994). Statistisches Jahrbuch 1994 für die Bundesrepublik Deutschland. Metzler Poeschel: Wiesbaden.

Strauss, A. L. (1987). Qualitative Analysis for Social Scientists. Cambridge: Cambridge University Press.

World Health Organization. (1995). World health report 1995 . Geneva: WHO. 